\title{
Impact Fatigue Failure of Ordnance Components
}

\author{
Frederick E. Schmidt, Jr. * and David M. Norfleet* \\ * Engineering Systems Inc., 3851 Exchange Avenue, Aurora, IL 60504
}

As far back as the origin of the industrial revolution, ordnance components have been at the center of manufacturing performance. Eli Whitney and a consort from New England were credited with the first demonstration of interchangeable parts to the Centennial Congress shortly after 1778, for muzzle loader rifles. Today, modern industrial components that require resistance to reversing inertia and dynamic forces require non traditional component design paradigm values: e.g. high speed reciprocating mechanisms for vehicles, textile handling, and polymer processing; firearms; and most secondary metal processing equipment.

These design parameters are not adequately predicted by handbook fatigue data on cyclic testing. Crack growth rates in well defined finite element stress fields are still inadequate to predict service life for dynamic and repetitive impact loading. The best way to accurately measure component performance vs. design requirements is to conduct life testing.

Design Strategy Options - Among the most effective techniques to improve impact fatigue resistance are: the utilization of advanced coatings, shot peening, autofrettage ${ }^{(1)}$, and cryogenic treatment. In this paper the use of metal injection molding (MIM) and development of an ultra fine grain microstructure was used to improve component life. The application is an extractor used in a conventional firearm to remove shells from the breech. An iron plus $2 \%$ nickel alloy was selected because it could be processed to retain a uniform fine grain structure.

Life Test Failure Analysis - The subject extractor was live fire tested to failure in excess of 50,000 cycles. This may seem to be a low total cycle failure, but not in light of the high rate of fire and impact loading. However, in this application typically the life expectancy is 5,000 to 10,000 cycles to failure with alloys like AISI 8620 carbo-nitrided case hardened, or AISI 1040 shot peened.

Previous fractographic ${ }^{(2)}$ studies performed on ordnance components indicate highly localized stresses develop and under impact loading non traditional macro and micro structure characteristics are observed. Figure \#1 shows a side by side view of a new and failed extractor. The actual fracture is at the middle of a large radius fillet (arrow). The new part has a claw which obscures the fillet view. Significant burnishing (wear) has occurred in the fillet area in the failed part, but this polishing actually mitigates the crack initiation stage in impact fatigue. Figure \#2 shows a macro view of the fracture path, with many traditional crack arrest indications of progressive fracture. The general fracture surface was remarkably flat and smooth even through to final fracture. Using the SEM it was determined that while some progressive features were observed as shown in Figures \#3 and \#4 at $500 \mathrm{X}$ and 1,250X respectively. In general a rumpled and mottled surface character occurs without any indication of fatigue striations. These components are exceedingly uniform in microstructure and exhibit a hardness level approximately $\mathrm{HRC} \sim 44$ to 51 as determined using Superficial Hardness.

[1] T. E. Davidson, et al, Case Histories in Fracture Mechanics, AMMRC, p.3.9.1, (1977)

[2] R.W. Hertzberg, et al, Fatigue \& Fractography, ASTM J O T E, pp. 261-271, Sept. (1989) 


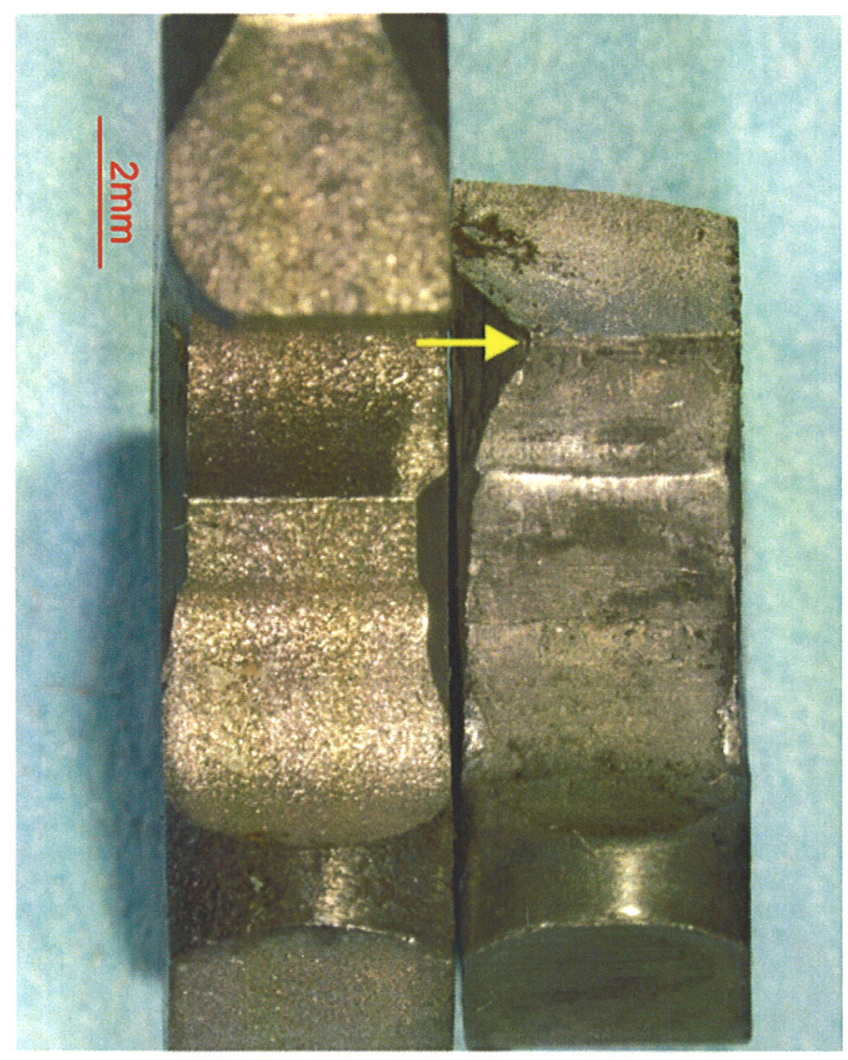

Figure 1 MIM, Fillet (arrow)

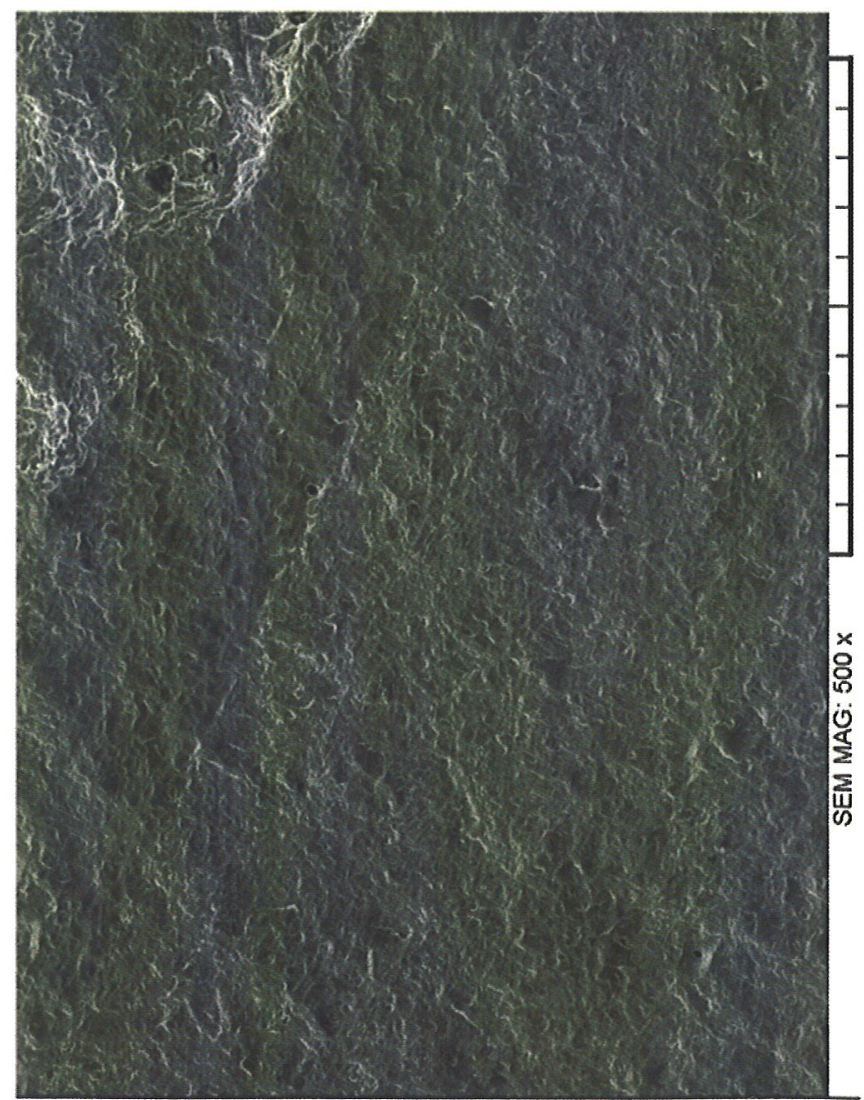

Figure 3 No Striations

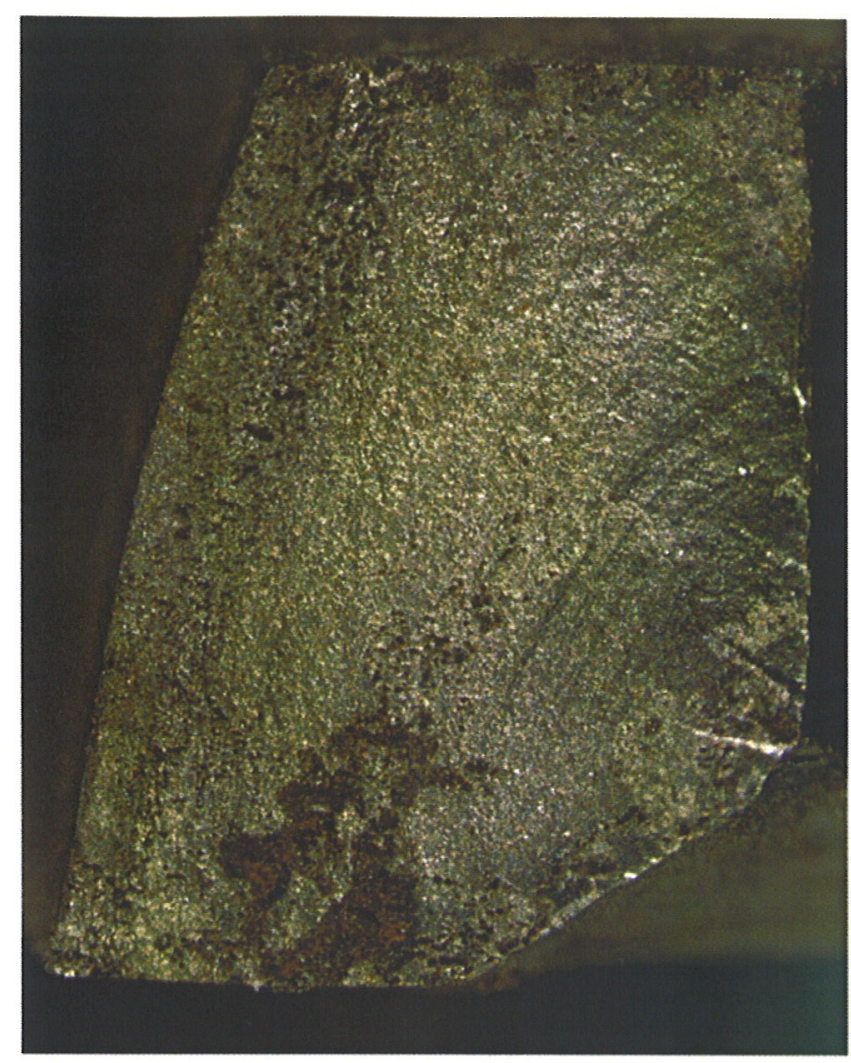

Figure 2 Crack Arrest Lines

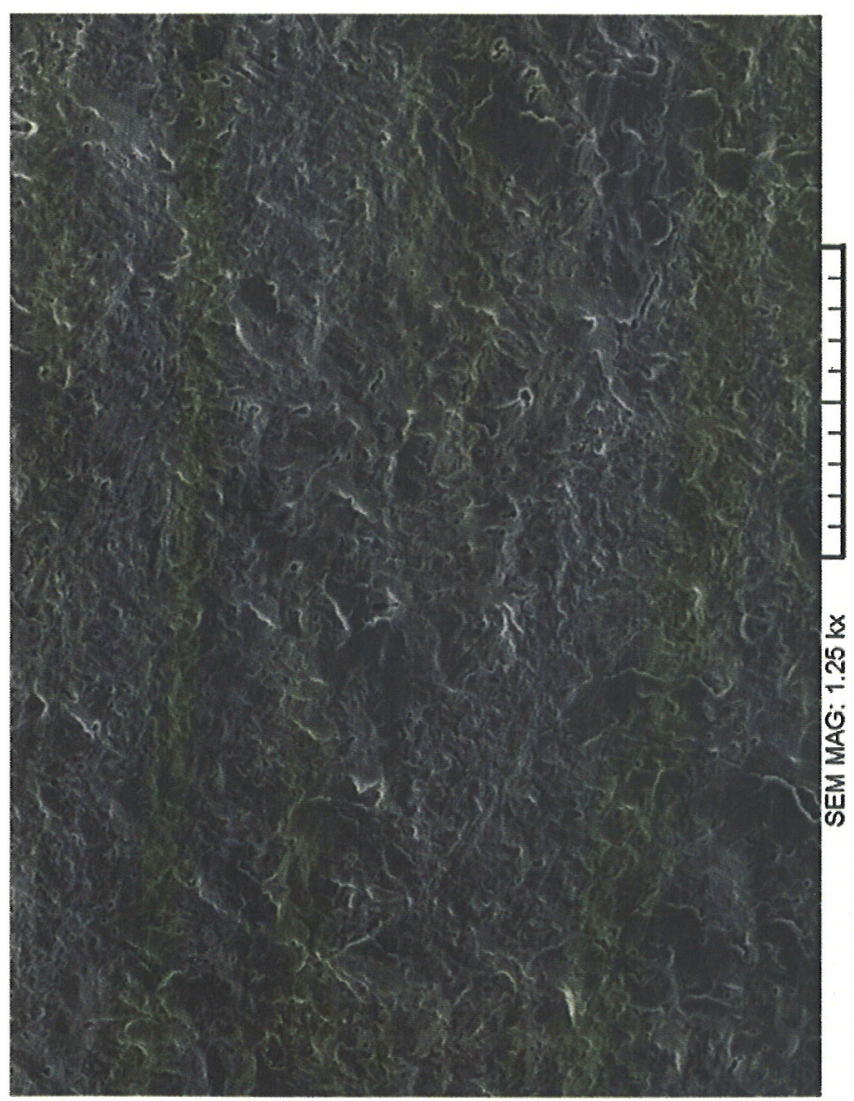

Figure 4 Rumpled/Mottled 